\title{
Defusing the energy trap: the potential of energy-denominated currencies to facilitate a sustainable energy transition
}

\author{
Sgouris Sgouridis* \\ Masdar Institute of Science and Technology, Abu Dhabi, UAE
}

\section{Edited by:}

Léo Benichou, The Shift Project, France

Reviewed by:

Subbu Kumarappan, Ohio State University Agricultural Technical Institute, USA

Sebastian Mayr, Sciences Po, France

*Correspondence:

Sgouris Sgouridis, Masdar Institute of

Science and Technology, P.O. Box

54224, Abu Dhabi, UAE

e-mail:ssgouridis@alum.mit.edu

\begin{abstract}
The universal adoption of fiat currencies and of the fractional reserve banking system coincided with access to and ability to utilize energy-dense fossil fuels leading to unprecedented rates of economic expansion. The depletion of economically recoverable fossil fuels though sets the stage for systemic crises as it is not adequately priced in the current market system. An energy-based system of exchange can be adopted in parallel to or in place of fiat currencies in order to facilitate a sustainable energy transition (SET) and mitigate the impacts of such crises. Energy-backed and energy-referenced currencies are discussed as two possible variants for their ability to realign the economic system to the thermodynamic limits of the physical world. The primary advantage of an energy-referenced currency over the current mechanisms for SET (like feed-in-tariffs or carbon taxes) is realized with the decoupling of the monetary and credit functions, especially when debt is tied to future energy availability. While energy-backed (credit) systems can be easier to adopt on a regional scale, the full transition to an energy-reference currency system requires significant reform of the financial and monetary system although it would not radically disrupt the current economic valuations given the high degree of correlation between value and embodied energy.
\end{abstract}

Keywords: energy currency, energy transition, energy economics, renewable energy

\section{INTRODUCTION}

An energy-denominated currency can be defined as a system of exchange that uses a unit of energy to measure the value of transactions in part or in whole. This paper explores the hypothesis that an energy-denominated currency system (e-currency henceforth) can be a versatile and effective mechanism for facilitating the sustainable energy transition (SET) of market-based economies reaching peak fossil energy availability. E-currency variants, a concept within the growing family of alternative currencies, seem to be uniquely able to tie two key problems of the sustainability question for our societies that are, so far, addressed separately, if at all. The first is sustainable resource valuation and management under climate and depletion constraints and the second is stability mechanism that can contain the financial system within the limits of the ecosystem.

In order to explain the significance of this statement, we provide a summary exposition of the dynamics of SET and the reasons why a significant acceleration of the global SET is necessary before proceeding onto the primary focus of the paper which includes a review of the types and mechanics of energy currencies and their impact on SET compared to the currently available policy options.

\section{ENERGY ECONOMY INTERACTIONS AND LIMITATIONS OF CONVENTIONAL NATURAL CAPITAL ACCOUNTING ECONOMICS}

Energy is a key resource (factor of production) in any type of economy and therefore a key limiting factor to economic development (Hall and Klitgaard, 2011). In pre-industrial societies, energy input was proportional to the amount of productive land available, as the primary energy resource was biomass for food (human labor and animals) and fuel with limited inputs of wind (primarily for sea transport) and water (mills). The industrial revolution fueled by fossil energy upended this status permitting unprecedented rates of economic expansion (Wrigley, 2010). Energy-dense fossil fuels prevented severe fuel shortage from extreme deforestation in Europe (Tainter, 2004) and provided the energy growth rate necessary to create an expansionary debt-based, financial superstructure. In addition, the availability of surplus energy resources (as evidenced by the low cost of fossil fuel for most of modern history) gave post-industrial revolution societies the possibility to effectively experiment with new ventures in the process of creative destruction as described by Schumpeter (Hart and Milstein, 1999). This era of economic expansion reliant on increasing availability of energy resources is coming to an end as fossil fuel extraction reaches its peak (cf. Bardi, 2009; de Almeida and Silva, 2009) and the associated greenhouse gas emissions accelerate climate change (IPCC, 2007).

Economic literature on natural capital accounting, while correctly framing the problem of transition fails to properly incorporate these physical limitations. Common and Perrings (1992) note that a self-regulating economic system should be based on consumption and production "objectives" that are sustainable. They use vectors representing resources and define welfare over a finite planning period to include both the current resource base and the future state of the system. With these they formulated 
economic and ecological optimality conditions for a sustainable transition. The economic part was based on Solow's formulation of the Hartwick rule: "consumption may be held constant in the face of exhaustible resources only if the rents deriving from the use of those resources are reinvested in reproducible capital" and assumed a condition on prices (the Hotelling rule) that states that the price of an exhaustible resource should be increasing at the rate of interest. They conclude that "consumer sovereignty," or market-based price adjusted resource valuation, is unlikely to reflect optimal valuation of the natural capital and therefore recommend external forcings (price setting, property rights re-allocation, etc.) to manipulate the broader societal optimal capital valuation.

Using a similar framework, Arrow et al. (2012) define sustainable development as maintaining the value of "comprehensive" wealth (capital goods, human and natural capital, knowledge, etc.). They formally define intergenerational well-being as the discounted flow of utility from all consumption in an economy and posit that it would be sustainable if its rate of change over time remains positive. They utilize current prices for valuing energy inputs (natural capital) and capital gains under the assumption that future scarcity is factored in the price of the non-renewable resource. The fallacy of this assumption is demonstrated when looking at the results calculated for the USA for the years 1995-2000 - in their accounting framework, the total extraction of the studied non-renewable resources (oil, natural gas, copper, lead, and phosphate) is counterbalanced by the perceived increase in the value of timber stock (and forest enjoyment) due to a marginal increase in forest cover! Aside from the fact that if the analysis was conducted with 2005-2010 prices, the result would have been reversed, it is problematic to assume that the depletion of essential factors of production for all physical economic activity from transportation to electricity and fertilizers is balanced by forest cover increase with a thermal energy content that is orders of magnitude lower and cannot be used directly for any of these activities.

\section{BIOPHYSICAL ECONOMICS AND THE FINANCIAL SUPER-STRUCTURE}

Barca (2011) notes the differences between conventional economic narratives as described earlier and the biophysical approach to economics. Frederik Soddy was perhaps the earliest economist to point out the physical incongruity of financial assets that have an ability to provide an indefinite stream of income seemingly superseding physical laws to which all other real assets are subject to (Daly, 1985). When looked from the energy thermodynamics perspective, the unsustainability of an exponentially growing system becomes self-evident and hence the calls for transition to a steady state economy (e.g., Daly, 1996, Part II, Ch. 4; Georgescu-Roegen, 1993).

The disconnect between the financial valuation of natural assets and their importance in economic processes can be empirically demonstrated. Hamilton (1983) observed that energy prices impact economic activity proportionally more than their nominal economic share would imply using standard economic models (e.g.). Alternative models involving either imperfect (Rotemberg and Woodford, 1996) or perfect competition and endogenous energy to capital interactions (Finn, 2000) have been proposed to explain this effect. Later, Hamilton (2009) notes the qualitative change of the 2007-2008 oil price shock that came from a physical rather than a political supply constraint as opposed to previous oil crises. He indicates a connection between the financial system and the energy system as the 2007-2008 energy price spike was exacerbated by speculative activity which was, in turn, facilitated by the low interest rates of monetary policy. Murray and King (2012) echo Hamilton and note that the relationship of oil supply and oil prices is undergoing a phase transition changing from elastic to inelastic since 2005 .

Explicitly connecting energy availability and the money supply, Douthwaite (2011) suggests that the growing supply of money in a fractional reserve banking system that sustains a higher rate of loan creation than debt repayment can only be supported through " more energy [that] could be produced from fossil fuel sources to give value to that money." The correlation between - artificially constrained energy availability (OPEC oil crises of 1973 and 1979) and economic recessions is indicative to this effect. In the past two decades, the increase in money supply from loan creation resulted in asset appreciation (bubbles) and increase in consumption worldwide. However, the effectively inelastic supply of liquid fossil fuels resulted in increasing oil prices. These did not immediately register as inflation due to the increasing share of low cost production in China and other developing countries and the recycling of the developing countries export surpluses in the form of loans and investments (capital) toward the developed world. This cycle of debt-supported consumption of energy imports either directly or embedded into products was shaken during the ongoing crisis.

In summary, there is strong evidence that: (i) the contribution of energy resources to the economic system is undervalued and (ii) that the debt-based, expansionary financial system relies on the implicit expectation of available future energy streams to support economic growth and remain solvent. Therefore, if the continuous increase in energy resources, which mainstream economic thinking and energy planning takes as given, is disrupted then the economic wealth of nations can severely devalue. As we discuss in the following section, the systemic undervaluation of energy inputs in the current economic system and debt over-extension are setting the stage for such a critical market failure.

\section{ENERGY TRAP AND THE SUSTAINABLE ENERGY TRANSITION}

Given the tight coupling of energy and wealth, in an environment where the monotonic increase of energy availability is bound to reverse it is critical to track the amount of net energy available (i.e., energy whose use is discretionary after all the operational and capital amortization needs for producing it are accounted for). This section discusses a simple net energy model framework to provide a context for the definition of SET.

\section{A BASIC ENERGY AVAILABILITY FRAMEWORK}

Gross energy available to society over any given time period is equal to the energy derived from fossil/finite fuels $(\mathrm{EF})$, the non-biomass renewable energy (ER), and the biomass energy (EB) for both food and fuel. In order to find the net energy available, we would need to subtract the energy inputs for the production of each. The energy inputs for extraction/growing and refining/processing of fossil and EB resources are largely concurrent to their use during an annual 
cycle. For renewables, on the other hand, the concurrent energy requirements are negligible compared to the energy expended during their construction, which is the most energy-intensive part of their lifecycle. As a result, it is the current investment in renewable generation infrastructure $(I)$ that needs to be subtracted to form the net energy equation (Eq. 1).

$$
\text { Enet }=\text { EFnet }+ \text { ER }-I+\text { EBnet }
$$

The net fossil fuel energy (EFnet) available can be represented as an aggregate of the extraction rates of fossil energy resources adjusted for the energy return on energy invested value (EROEI) by fuel type at that period (Dale et al., 2011). A robust estimate of the extraction rate of a depleting resource is offered by the Hubbert curve (Maggio and Cacciola, 2009) and its parameters can be calibrated for the different resources (i.e., oil, coal, natural gas) yielding a composite fossil fuel Hubbert curve when summed. In addition to depletion dynamics, the extraction of fossil fuel resources may be curbed as a result of climate-related constraints giving a lower peak and steeper drop compared to unconstrained extraction.

In turn, the gross EB yield is dependent at the most basic level on: cultivated land area $(A)$, average yield $(y)$ (a function of cultivation technology, energy and labor inputs, climate, etc.), and average energy content (eb) of the crops per unit of harvested mass. From this, we need to subtract the direct (e.g., fuel for machinery and transport) and indirect (e.g., fertilizer and pesticide production) energy inputs (EBin) as shown in Eq. 2. While the majority of the caloric content of agricultural biomass yield is consumed as food and fodder, a portion $(\beta)$ can be diverted for use as fuel ${ }^{1}$.

$$
\mathrm{EBnet}=\text { Ayeb }(1-\beta)+A y \mathrm{eb} \beta-\mathrm{EBin}
$$

Combining and rearranging Eqs 1 and 2 to separate the primary energy available for use as fuel (Etech) and for human and domesticated animal consumption (Efood), we arrive at Eq. 3.

$$
\text { Enet }=\underbrace{\mathrm{EFnet}+\mathrm{ER}+A y \mathrm{eb} \beta-\mathrm{EBin}}_{\text {Etech }}-I+\underbrace{A y \mathrm{eb}(1-\beta)}_{\text {Efood }}
$$

The amount of ER investment is discretionary and can be written in relation to the available energy (Etech): $I=\varepsilon$ Etech, where $\varepsilon$ is the ER investment ratio. A detailed analysis of the net energy equations calibrated to real-world data is provided in Sgouridis and Csala (under review). Other tools like the Rogeaulito (Benichou and Mayr, 2014) also identify the potential missing energy supply in future energy availability forecasts. In order to illustrate the dynamics of the energy transition, we present an indicative Etech curve for an energy system that transitions from a fossil fuel base to a ER base at a constant value of the ER investment ratio $\varepsilon$ (in the illustrated case, $0.4 \%$ which is the actual current value) showing both the unconstrained depletion trajectory of a composite Hubbert curve and one constrained by climate-driven limits in the use of the fossil resource.

${ }^{1}$ Of course the entire nutritional value of agricultural productivity is not represented in the energy content. Nevertheless, the energy content is a clear indicator of the human activity that can be supported.

\section{THE ENERGY TRAP}

For several decades prior to the net energy peak, energy availability is increasing and slowly plateauing creating an institutionalized expectation that it will continue to behave this way. The pace of market-driven ER investment is accelerating but it proves insufficient to compensate for the reduction following the fossil fuel (actual or climate-constrained) peak. With insufficient renewables built before peaking, the only option for maintaining energy availability post-peak is to raise the investment ratio $\varepsilon-$ an action that further reduces the net available energy at the time of such investment ${ }^{2}$.

In practice, raising the investment ratio $\varepsilon$ after the fact is may be too costly as it effectively increases the perceived energy costs for the entire economy to socially unacceptable levels. A more likely result is a reinforcing cycle of demand destruction (due to high energy costs) and a drop in actual energy investment since, in a situation of dwindling resources, satisfying immediate needs becomes a priority thus diminishing the ability and willingness to invest in renewable resource infrastructure construction. This is the energy trap: the non-renewable resources are allowed to deplete without commensurate investment in renewable resources locking in a lower energy availability state, the scenario shown in Figure 1.

The energy trap is sprung when an economic system is loosely coupled to the limits of the ecosystem it is embedded in. This happens because of the combined effect of a market failure in pricing the resource before the peak and the parallel over-extension of debt-based on the past expectations of economic performance. This combination creates a phase of over-consumption of available resources and under-investment in ER infrastructure, locking in both high-consumption habits and inefficient infrastructure. The trap closes when, with resource limits exceeded, the cycle of contraction leading to further under-investment in transition mechanisms and further contraction becomes self-reinforcing ${ }^{3}$.

\section{DESIGNING AN ECONOMY FOR THE SUSTAINABLE ENERGY TRANSITION}

The SET can be defined, as a controlled process that leads an advanced technical society to derive all of its energy needs from renewable resources while maintaining sufficient final energy services per capita. The main characteristic of ER generation - for current and foreseeable technologies - is that they have a strong capacity constraint (i.e., they are power limited) and any capacity expansion to cater to increasing energy demands entails significant upfront investment and a construction lead-time. These resources

\footnotetext{
${ }^{2}$ This paradox is observed today with the net energy payback from solar PV installations - it remains negative so far due to the very rapid increase in the PV installation rate (Dale and Benson, 2013).

${ }^{3}$ A preview of how the trap may operate can be found in the impact of the "great recession" on the Greek society. The housing and transportation infrastructure was built during a time of cheap energy imports available on credit even while maintaining negative current account balances. When borrowing costs rose - concurrently with energy prices, the ability to switch to more energy efficient infrastructure and import substitution (e.g., insulating the housing stock, electrifying public transport, building domestic renewable energy capacity) became severely limited and contraction (demand destruction) followed. While the situation is complicated and energy, in this case, is but one factor, the pattern follows the energy trap mechanism described.
} 

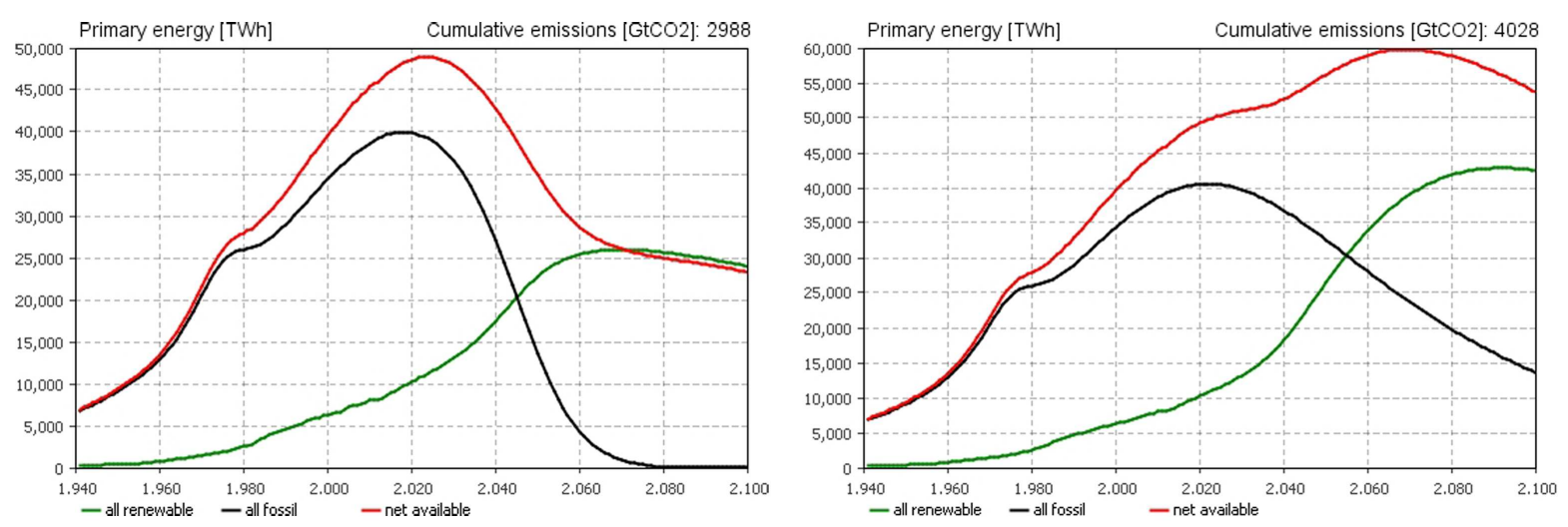

FIGURE 1 | Available energy dynamics for investment ratio $\varepsilon \quad 0.4 \%$ and EROEI $R_{\mathrm{r}} 15$ carbon constrained (left) and unconstrained (right)

are called to replace a fossil fuel-based energy system that throughout its history could increase power output with bounded cost through increasing the extraction rate from already discovered reserves. In other words, SET is a transition from a paradigm where power demand was always lower than capacity to a paradigm that energy consumption is limited by the installed base of generation - a transition from an economy of energy stocks to an economy of energy flows capped at any time by the stock of installed generation capacity.

There are two options for addressing this challenge and avoid the energy trap: self-regulating market mechanisms and/or government intervention. As indicated in Sections "Biophysical Economics and the Financial Super-Structure" and "The Energy Trap," there are systematic market failures in operation. At a fundamental level, they are based on the unstated assumption that the available energy supply in the future can expand practically as needed. This assumption permits a destabilizing level of unproductive investment through financial speculation and an overshoot in the amount of virtual wealth registered in the financial system compared to the ability of the actual economic system to provide it.

Implicitly recognizing that unregulated markets fail to effectively price climate and SET constraints, governments have installed a number of regulatory mechanisms that initiated the transition. These include externality pricing systems like emissions trading (Haar and Haar, 2006; Ellerman and Buchner, 2007) and taxes (Pearce, 1991; Zhang and Baranzini, 2004), positive incentives like feed-in-tariffs (FITs) (Kim and Lee, 2012) and targets for ER implemented through systems like ER quotas [cf. Butler and Neuhoff, 2008 for a comparative review of FIT and energy targets/quotas (REQ)].

These mechanisms had an unquestionably positive impact in the development and adoption of ER technologies. Nevertheless, the need for a coherent energy policy and groundbreaking rethinking of policy mechanisms is recognized (Doukas et al., 2008, 2010). Importantly, the targets that these policy mechanisms operate on are arbitrary and seem insufficient to defuse the energy trap on a global scale. At the current rate of ER investment and with climate constraints active, the per capita available technical energy (Etech) at the end of the century could be four times lower than the per capita energy available today (cf. Figure 1).

An economic system that operates within the actual ecosystem boundaries should be able to:

- Allocate resources prioritizing sustainably productive investment.

- Ensure sufficient energy in the future to satisfy current growth commitments (debt).

- Limit (but not eliminate) speculative activity to use only excess net available energy.

- Ensure that nominal wealth does not exceed the productive capacity of the economy.

- Incorporate feedback mechanisms that operate proactively and autonomously rather than relying on external intervention.

These functions would be common to both a closed (i.e., no imports/exports) and an open economic system. For an open economic system, like the national and regional economies inside the global trade system, an additional function needs to be realized the ability to account for the non-ER footprint of imports and a way of biasing the economy toward lowering it.

In the sections that follow, we review the energy currency concept and discuss how it could work toward these goals, explore its implications on the energy system, and its integration with the macro-economy.

\section{MONEY, ALTERNATIVE CURRENCIES, AND ENERGY CURRENCY}

Wealth is a measure of a society's ability to harness physical resources to satisfy the needs and desires of its citizens. A monetary system, according to Jevons (1885), reflects societal wealth by providing a measure of value and a (notional) store of wealth. In addition it is a means of exchange and a means for deferred payment. Commercial transactions were conducted for millennia through credit arrangements (not barter!) usually denominated in commodities like cattle and grain and which were soon formalized into currency (Graeber, 2011). This commodity basis was gradually switched to metals. For a significant period of the twentieth 
century, the Gold Standard was the mechanism through which countries controlled their domestic money supply and which allowed for the valuation of the exchange rates between currencies for international trade. It provided long-term price stability and facilitated international trade. Yet, when the rate of increase in the global money supply is coupled to the gold extraction rate it decouples from the economy (and creates demand for an unproductive activity - gold extraction). If the supply increases slower than the productive capacity of a growing economy it results in constraining capital formation causing deflationary pressures or inflation otherwise (Bayoumi et al., 1996, Ch. 3). Since the economy exhibits endogenous and exogenous cyclicality, the rigidity of the money supply prevents a central bank from increasing it by lowering interest rates to alleviate the effects of a downturn. In part due to these issues, the gold standard gave way to a purely fiat money system under a fractional reserve banking system.

Lietaer (2001) quips that modern money is "a belief about a belief" referring to the willingness of trading parties to accept money as compensation in the expectation of receiving equivalent services at a later time. In the conventional monetary system based on fractional reserve banking, the broad monetary supply is dependent on bank lending and therefore is only loosely controlled by the interest rates set by the central bank and the regulated capital and reserve requirements.

The boom and bust excesses resulting from the uncontrolled credit supply of the banking system were noticed even without a binding energy constraint. Starting as a response to the great depression, on the monetary theory side there is recognition that the monetary and credit functions should be decoupled which became known as the Chicago Plan (Allen, 1993; Benes and Kumhof, 2012) ${ }^{4}$. Benes and Kumhof suggest that the monetary supply should be adjusted through monetary policy alone and not through practically unconstrained loan creation as in the current fractional reserve system. In other words, credit could be extended only if another party, depositors public or private, is willing to forego the "benefit of real economic transactions" by depositing existing government-issued money. Traditional banks would become investment trusts that issue equity. In that way, the aggregate money supply in an economy under the Chicago Plan would be solely controlled by the government, which would need to continually monitor and adjust it to avoid excessive deflation or inflation but it would not be tied to a physical commodity, either.

Complementary or alternative currencies - with Local Exchange Trading Schemes (LETS) and time banking being the most widely adopted - were also a response to deficiencies of conventional money - namely perceived lack of liquidity in the local economies. At their basic, a network of businesses and individuals within a community agree to accept the alternative currency as a form of payment for services in the expectation that they will be able to redeem them later within that community (North, 2006). A more recent form of alternative currency, the bitcoin and its derivatives, is based on the ability to formulate algorithmic scarcity, creating an artificially constrained supply of electronic

${ }^{4}$ It is interesting to note that the concept originates with Frederick Soddy (cf. see Biophysical Economics and the Financial Super-Structure). tokens that can be used as a medium of exchange but which has no intrinsic value (Nakamoto, 2008) - similar to the Gold Standard, bitcoins are constrained by the rate of "mining" rather than the needs of the economy. The primary attraction in this case being the anonymity of electronic transactions that can happen outside the conventional banking system.

\section{ENERGY CURRENCY CATEGORIZATION}

E-currency concepts are a part of this growing family of alternative currency movements. Collins et al. (2012) provide an overview of a large and varied number of e-currency proposals and recent concept papers are also available from the first topical conference (ISTC, 2012). E-currency configurations can differ significantly in implementation, scope and, by implication, in their potential effects on SET. A categorization with regard to the key parameters can therefore be helpful. Building on Collins et al., we identify the following differentiating characteristics that define the relationship of an e-currency to the energy and economic system:

- Objective: the primary purpose of the introduction of the ecurrency. It could be energy project financing, short-term energy use management, or long-term alignment between the economic and biophysical system.

- Reference: the question of whether the e-currency is backed by the energy resource and can be redeemed for energy at nominal value (energy-credit) or if it is pegged to the resource but not directly redeemable (energy-referenced).

- Scope: E-currencies can be issued based on renewable resources, fossil resources, or a combination. For energy-backed currencies energy should be measurable, distributable, and exchangeable. The e-currency scope can be extended to cover all energy sources (i.e., including food and traditional biomass) for energy-pegged currencies.

- Accounting: E-currencies could represent primary energy at the generation/extraction level, final energy at the consumption level, and can be adjusted for exergy or simply use calorific value.

- Timescale: E-currencies may capture only current energy flows (power) or account for future energy production (reserves, yet-to-be built capacity).

- Scale: an e-currency could represent a portion of the societal energy usage or its entirety. It could also be a regional, national, or international solution.

- Transactions: E-currencies can be used to cover only energy services or extend to non-energy transactions.

- Governance: the governance architecture could be centrally controlled, or issued on peer-to-peer basis with third-party oversight. Related to scale, national governments, municipalities, corporations, and citizen co-ops could mobilize in issuing and regulating e-currencies.

Using the reference characteristic, we discuss the existing currency concepts under the two approaches: energy-referenced and energy-backed.

\section{ENERGY CURRENCY CONCEPTS}

Energy-referenced currencies are coupling the monetary system to the physical limitations of an economy as an accounting unit 
but are not directly redeemable to energy at nominal value. In fact, the denomination of the currency does not have to be strictly in energy terms as long as there is rigorously defined equivalent exchange rate. The theoretical potential of energy-referenced currencies was explored early on (Scott, 1933) from the viewpoint of including energy in a basket of commodities that define the money issued. Variations aside, later proposals like Douthwaite (1999) with the ECBUs concept, Lietaer (2001) with the Terra, and Turnbull (Benello et al., 1989) echo this early call, as they fundamentally propose that rather than an arbitrary value, the quantity of money should be pegged to actual energy generation, in total or as part of a basket of commodities. In that case, an energy-referenced currency would entirely replace conventional fiat money and can only be issued by government authorities (topdown). Energy accounting for energy-referenced currencies would be done on a broad scale using primary energy estimates (similar to those available from energy and food statistics like IEA, EIA, FAO, etc.).

Contrary to energy-pegged currency concepts where the money supply is tied to energy availability but the money itself is not directly redeemable, energy-backed currencies are exchanged for the actual energy they represent. By implication, energy-backed currencies can be bottom-up efforts at different scales but they can only be complementary currencies, operating in parallel to the conventional monetary system.

Collins et al. (2012) outline a number of energy-backed community currencies that aim to support a portion of the energy needs on a local scale with a focus on ER project financing. These are small, community-scale, efforts to support the construction of ER project(s) by issuing certificates based on future energy generation. They can circulate as community currency and can be redeemed in exchange for energy or other goods. Energy accounting in energy-credit systems needs to accurately reflect the net energy availability for the end user of the credit system accounting for transmission and processing losses. It would be similar to the measuring and calculation of energy consumption at the electricity meter or fuel pump.

Credits are issued based on actual energy generation and system users can surrender/debit them in exchange for energy services and in proportion to the energy quantity required for that service. By definition, energy-credits are withdrawn when used in exchange for energy and therefore they must be continually issued to match exactly the rate of energy generation. This connection between the energy use and credit issuance can be leveraged to support rigorous short- and medium-term energy management. Tradable energy quotas or TEQs (Fleming, 2005) is a system proposed for phasing out the use of fossil fuels in the UK. The Ergo (Sgouridis and Kennedy, 2010) is a credit system that aims to cover the entire energy use for communities with hard energy targets (Masdar City in that case) but also provides a bridge to an energy-referenced currency system. A key difference between the two proposals is that while Ergos represent the actual ER generation budget of the community, TEQs represent (diminishing) entitlements to fossil-based energy that can be auctioned and traded among users making scarcity the reason for switching to renewable alternatives. In the following sub-section, we elaborate further on the mechanics of the Ergo as a case of an e-currency that illustrates a possible progression from energy-backed to energy-referenced monetary system.

\section{PROGRESSION FROM CREDIT TO CURRENCY FOR THE ERGO CONCEPT}

The fundamental principle of the Ergo concept is that it should reflect as faithfully as possible the key attributes of the actual energy system in which it is implemented. As such, its primary objective is energy resource management. Ergos (energy-credits) should: (i) be issued against the actual primary energy supply capacity adjusted for exergy under clear accounting rules, (ii) expire upon use and have a preset validity period, (iii) be traded in asymmetric markets where users that have exceeded their allocated amount can only buy Ergos at the spot market price at the time of use. The Ergo system was envisioned to support communities that have to maintain a binding energy constraint.

\section{Ergo concept overview}

The Ergo system is a dual-currency system designed to cover the energy component of transactions (and not non-energy value-added). As a result, even for transactions that are purely energy consuming (e.g., electricity or transport) the non-energy component will still be covered by conventional currency.

Ergos represent an energy unit (e.g., joule or kilowatt hour) and are issued to equal the total quantity of primary energy available to the community. The amount of available energy that reflect the planning and capacity limits is allocated over the budgeting period and distributed across the user base. Allocation frequency depends on the expiration period. The reasons for designing in an expiration are twofold: (i) ER is expensive to store over long periods - this may be less of an issue for cases with high penetration of fossil fuels or cheap storage and (ii) the psychological effect of strong future discounting - it is unlikely that users given their full annual Ergo allotment would be able to provision and plan for their consumption something that is easier with daily or weekly allocation. Additionally, anticipating the transition to a currency, an expiring unit, similar to a depreciating one, prevents hoarding and limits the potential for a speculative market. Allocation among users can be equitable or follow a subscription-based system with tiered categories (akin to a cell phone plan) depending on user needs.

The key to the success of any demand side management system lies with the ability to match the signal to the desired outcome; in this case, staying within a predefined energy budget. Every Ergo user and service provider has a dual account of Ergos and conventional currency. As the user consumes Ergos for energy services throughout the Ergo validity period, the cumulative consumption is registered in an asymmetric market for Ergos. This market values Ergos in conventional currency but imposes a key limitation on buying discussed below. While the cumulative demand matches the forecasted demand profile the price of Ergos is stable. Ergo prices change as there is divergence, i.e., if Ergos are retired earlier than planned then their price rises or conversely if there is a surplus their price is reduced. Since this is a function of cumulative consumption, it presents a slowly varying signal rather than the faster fluctuations of a real-time pricing system.

The Ergo system subscribers can access and monitor their Ergo account through a programmable web-enabled interface on a 
smart device. Through it, they can participate in the market by setting a trading level for when the prices of Ergos on the spot market rise above reservation price. In that case, Ergos from the user's account are sold on the market and the monetary price is deposited to the user's current account. What makes the market asymmetric is the fact that the user cannot speculatively buy Ergos without immediately retiring them for an energy service. In this way, there is a choice for the Ergos that will be retired (from the user's account or from the spot market).

\section{Ergo debt and futures as bridge to energy currency}

Given that most initial real word applications would evolve around grid-connected communities with the option of using fossil fuels, a less restrictive approach would allow communities to balance their energy budget and meet their ER targets over longer periods. To moderate mid-term price volatility, Ergos could be issued on a deficit basis to effectively place an upper limit cap to the price of Ergos. Since Ergo issuance is transparent, this "energetic" balance (debt or surplus) becomes an indication of the sustainability of the community. Debts will need to be covered in the next budgetary period through additional investment in energy generation.

To further facilitate the long-range energy planning, Ergo futures could be issued and traded. These are Ergos that have a future activation date and represent all energy generating capacity beyond the current active Ergo trading period including planned future expansions and fossil fuel reserves that can be extracted. Unlike active Ergos, Ergo futures are traded actively and symmetrically and, therefore, can be banked. Once they become active they revert to being ordinary Ergos and the energy that they represent needs to be delivered when the Ergo is surrendered.

If such an Ergo system is adopted on a national scale, it becomes possible to integrate it with the national fiat currency system. The total supply of Ergo futures, possibly augmented by properly adjusted non-technical energy resources (e.g., food and biomass), can be used by the government controlled central bank to reference the monetary supply under a Chicago Plan monetary system (cf. see Introduction). This way the futures idea can connect the energy-backed credit concepts with a broad and full-scale e-currency. Under such a system, the total amount of credit line made available to investment trusts by the government treasury ${ }^{5}$ would be correlated to the net additional surplus of energy compared to current levels that is expected to be available in the period during which the debt matures (i.e., equivalent to Enet $^{t}-$ Enet $_{0}^{t}$ ).

Effectively, an energy-credit system represents the rate of energy consumption for an economy while an energy-pegged currency system tracks the productive capacity of the embedded energy in the capital stock in the economy (representing a gross domestic energy product) as well as the energy resource potential available for future expansion. In addition, an e-currency under a Chicago Plan monetary system that binds all issued debt to a fixed, energy-based monetary supply provides an unequivocal signal for

\footnotetext{
${ }^{5}$ It is reminded that under the Chicago Plan as described by Benes and Kumhof (2012) the only entities that can extend credit are investment trusts that can draw their funding from the government treasury and through deposits in exchange for equity from other agents.
}

investment capital to be directed toward future energy generation given that this directly increases the monetary supply.

\section{DEFUSING THE ENERGY TRAP: ENERGY CURRENCIES AND THE SUSTAINABLE ENERGY TRANSITION}

The different flavors of e-currencies as described above have a differentiated role to play in a SET. The simpler project financing energy-credit systems are the ones that are easier to implement (some are already active) and as such they provide a tool for: (i) financing ER projects and (ii) familiarizing communities with the possibility of denominating value to energy. These systems, though, do not have a feedback mechanism for adjusting the rate of SET nor do they limit debt issuance to the productive capacity of the economy - both critical functions for a SET.

Crucially for a local or regional scale transition effort, an ecurrency system would need to encompass all energy usage. Inclusive energy-credit systems, like the Ergo, which covers all direct energy inputs to the economy or the TEQ, which covers all fossil inputs, become useful options. Both of these systems are designed with a self-adjusting, market mechanism to provide continuous feedback to the economy with regard to whether direct energy use (only fossil in the case of TEQs) is in line with the targeted (or available) energy capacity. As a consequence, in addition to managing energy consumption, there is an implicit incentive for building up the local, ER supply to the point of reaching a local SET. This way, the energy targets for a renewable-based energy supply are not disengaged from the economy itself. While TEQs are only designed to manage the fossil fuel phase-out, the Ergo concept also provides active feedback mechanisms to achieve energy management in an economy of (energy) flow, specifically, by adjusting the issuance cycle and expiration date of Ergos in the asymmetric market (cf. see Ergo Concept Overview).

However, these credit systems lack an explicit coupling between the financial system expansion mechanism (debt) and the energy system that, as discussed, is a critical part of a successful SET strategy. In addition, while the energy-credit mechanisms can indeed manage the SET of the direct energy supply, in an open economy the energy balance embedded in imports and exports remains unaccounted. A Chicago Plan, energy-referenced, e-currency system as presented in Section "Ergo Debt and Futures as Bridge to Energy Currency" can provide the former. Addressing the issue of trade with economies that have not adopted an energy standard though, would require some type of energy auditing for imports, which could be complicated but not impossible technically and could function under currency exchange rules based on economic energy-intensity.

A possible argument against an e-currency is that it imposes undue constraints on monetary policy with associated problems like deflation and liquidity limits that may seem at first glance similar to the problems of the gold standard. This perception is incorrect as e-currencies have the advantage of being directly correlated to the true productive capacity of the economy at any given time and since inflation (or deflation) depend on the relative quantity of money and goods when the two are automatically correlated neither inflation or deflation should be expected.

In turn, the conventional mechanisms (cf. see Designing an Economy for the Sustainable Energy Transition) present 
significant weaknesses when it comes to SET. FITs that were instrumental in kick-starting RE adoption, are technology specific, therefore not encompassing the entire energy system, and they need to be actively reset as targets are reached. Given the piecemeal approach, FITs do not provide a mechanism to allow long-range transition planning as neither energy demand nor the price and availability of fossil fuels are accounted. Between the pollution reduction systems, Emissions trading schemes (ETS) excel in addressing emissions limits using concrete step-wise targets but they incentivize deployment of RE only indirectly. This is an issue during a recession when economic activity slows down allowing the carbon targets to be met without any substantive transition effort. Similarly, neither ETS nor carbon taxes can limit debt-fueled consumption. These issues are true for renewable REQ especially if set as a percentage of total energy use. An additional drawback particular to RE targets is that they are set exogenously. With a cumbersome and slow feedback, if any, targets may end up being too strict (resulting in lower economic benefit from sub-optimal use of the fossil fuel reserves) or, more likely, too lax (energy trap). In summary, there are two main drawbacks common across all conventional mechanisms: (i) there is no strong feedback on the rate of progress for energy targets, and (ii) they can be severely undermined by the financial cycle as they cannot curb misallocation of resources during credit booms and forced underinvestment during recessions.

Table 1 presents a comparative summary of the relative merits of the mechanisms discussed with relation to the SET and monetary functions. The greatest advantage of e-currency concepts with the characteristics of Section "Ergo Debt and Futures as Bridge to Energy Currency" is their ability to be encompassing, work in a long-range frame and be self-adjusting once initiated. They still require guidance and additional policy intervention in the area of environmental externalities and, of course, they may need significant time to be deployed given that they are not yet part of the mainstream policy options.

On the issue of adoption, lead adopters of energy-credit systems could be communities with a binding energy constraint and access to energy resources. The ideal community would have defined boundaries, be a fossil fuel importer, have access to ER resources, and binding ER targets. On the technology front, it would have an existing or planned smart grid deployment and a technologically savvy population.

Sgouridis and Kennedy (2010) developed the Ergo concept for application to the Masdar City - a mid-size development aspiring to be net zero carbon near Abu Dhabi (Reiche, 2010). Communities like Zug in Switzerland are engaging in a fundamental debate on whether to strive toward creating a 2000-W society (Marechal et al., 2005). The concept advocates that western societies should converge toward the estimated global average primary energy consumption per capita, which represents a $70 \%$ reduction from current energy consumption levels in Switzerland. The European Union as well as municipalities under the Covenant of Mayors are debating establishing higher ER penetration targets in the future. Any type of ER target, be it 20 or 30 or $100 \%$, once it becomes a commitment, places a limit in the actual energy available for consumption based on the capacity of ER generation (existing or planned) (Oikonomou et al., 2011) and therefore could be supported by an energy-credit type of system.

As we have seen, energy-credits and energy-referenced currencies can have very different scales. One way of converging from credits to currency was described in Section "Progression from Credit to Currency for the Ergo Concept." On the other

Table 1 | Comparison of sustainable energy transition fit.

$\begin{array}{lllllllll}\begin{array}{l}\text { Fiat currency } \\ \text { and energy }\end{array} & \begin{array}{l}\text { Feed-in- } \\ \text { tariffs }\end{array} & \begin{array}{l}\text { Renewable } \\ \text { energy }\end{array} & \begin{array}{l}\text { Emissions } \\ \text { trading }\end{array} & \begin{array}{l}\text { Carbon } \\ \text { tax }\end{array} & \begin{array}{l}\text { Limited } \\ \text { energy- }\end{array} & \begin{array}{l}\text { Full-converge } \\ \text { energy-credits }\end{array} & \begin{array}{l}\text { Energy- } \\ \text { referenced }\end{array} & \begin{array}{l}\text { E-credits } \\ \text { and }\end{array} \\ \text { markets } & & \text { certificates } & \text { schemes } & & \text { credits } & \text { (Ergo/TEQ) } & \text { Chicago } & \begin{array}{l}\text { Chicago } \\ \text { chican }\end{array} \\ & & & & & & & \text { Plan } & \text { Plan }\end{array}$

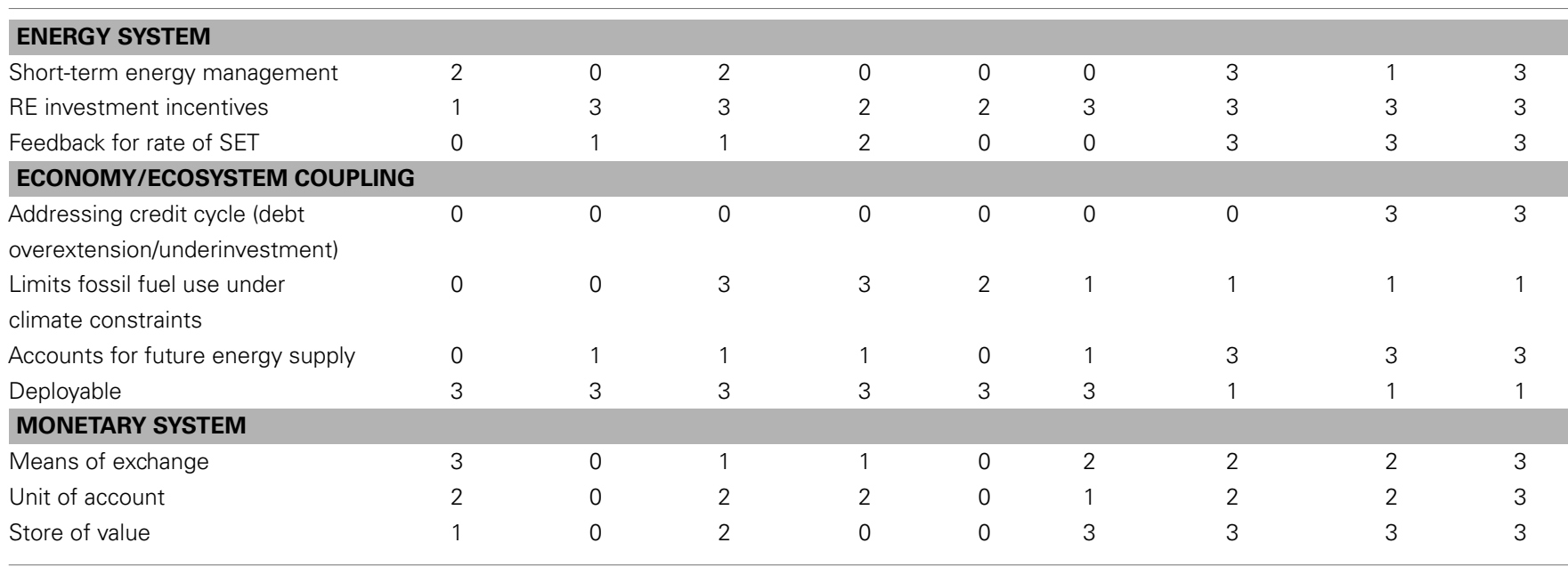

The number is an indicative estimate of the potential for each mechanism to meet the function: 3 indicates strong potential, 2 indicates sufficient potential, and 1 indicates limited potential. 
hand, the monetary system transition can be initiated on the governmental level independently. An energy-referenced currency under a reformed monetary system according to the Chicago Plan presents a much broader social transformation that is significantly disruptive to the current status quo. Addressing the complications and eventualities of the necessary organizational reform extends beyond the scope of this paper.

\section{INTEGRATION OF E-CURRENCY IN THE CURRENT ENERGY ECONOMY}

Having discussed the potential advantages and disadvantages of the various e-currency concepts for SET and in comparison with the conventional mechanisms in place, we turn on aspects of ecurrency integration with the existing energy economy nexus. Namely we discuss how much would the system of prices would be impacted and elaborate on the impact of e-currencies on the energy system.

\section{ENERGY CURRENCY VS. FIAT CURRENCY AS A UNIT OF ACCOUNT AND A STORE OF VALUE}

One way of assessing the potential impact of a widely adopted energy currency system is to examine the current relationship between the energy input and economic value of products and services. A consistent way to do so is to extracting the lifecycle total energy and total economic value component from economic input-output lifecycle (EIOLCA) accounts. We use the US 243 economic sector model based on the 2002 producer prices (CMUGDI, 2008). For every $\$ 1 \mathrm{M}$ of activity in each of the 243 economic sectors, we register the total economic value-added (i.e., the direct and indirect economic transactions across all sectors that result from the $\$ 1 \mathrm{M}$ seed activity). We also aggregate the total (direct and indirect) weighted energy input that is needed to complete this activity from all related sectors. The EIOLCA model breaks energy inputs into five categories (coal, natural gas, oil, bio/waste, and non-fossil electricity), which we weight with reference to the higher quality of available energy of electricity.

The results, plotted in Figure 2, show a strong correlation between energy inputs and total economic value but also a significant spread. Energy-intensive activities that provide the basis for the economy (i.e., the transportation, extraction, and power sectors along with some heavy-industry activities like smelting) are shown to have lower total economic value-added today. With increasing energy scarcity - i.e., higher energy prices, the correlation can be expected to tighten further as those activities will increase their premium. These results indicate that to a significant degree, energy-intensity already represents fairly well the economic value-added for existing activities.

As a unit of account, energy denomination of a currency would not drastically disrupt the majority of existing price relations but it could make relatively more expensive (internalize the externalities) activities that rely on readily available cheap industrial-scale energy sources. At the same time, neither an energy-referenced nor an energy-backed currency is subject to inflation and therefore a much more secure store of value than fiat currency. Of course, in the monetary system transition phase, the inability to increase the money supply freely is bound to create economic disruption as the cycle of new loans servicing older ones would be disrupted indicating that any such transition needs to be carefully orchestrated.

\section{ENERGY CURRENCY AND THE ENERGY SYSTEM}

On the e-currency relationship to the energy system, we have observed that energy-credit systems can be used for short-term energy management while energy-referenced currency for longrange energy planning of economic needs. This is fundamentally the result of a process that accounts physical input across the value chain in a way that enables a bottom-up energy audit of any economic activity. As consumer products and services become comparable against a common energetic value, the consumer choice will naturally gravitate to those that have the lower energy footprint. If implemented correctly, the use of energy quality as a weighting mechanism will increase the use of energy grades that are fit for purpose and limit the expense of high-grade resources to deliver low-grade heat.

This is in contrast to the way current liberalized energy markets operate. By seeking high financial rates of return for energy projects and in combination with the market failure in pricing fossil fuel depletion, they create a flawed preference for energy resources with lower EROEI as long as they offer a higher net present value. For example, by offering the bulk of the return early on, shale gas and tight oil resources show better financial payback over an equal investment in solar or wind projects that yields a higher EROEI (and no carbon emissions) over a 30-year lifetime but with a lower NPV. In an energy-constrained world, this is a sub-optimal resource utilization, which is addressed if energy becomes the reference point for monetary supply.

On the other hand, a question with regard to e-currencies is the handling of energy variability. Energy demand varies over time and with increasing penetration of renewables so does its supply. In electricity grids, this variability combined with marginal cost dispatch gives rise to the "merit order effect," i.e., instances where the spot price of energy becomes zero (or even negative with priority dispatch for renewables) as baseload producers offload the costs for throttling down their generation facilities. Conversely to the merit order effect, at times where demand is higher than capacity, spot prices can justify decisions to shift energy demand through inefficient storage to meet the power capacity limit. In both cases, energy's perceived market value is effectively variable dependent on the time of its availability being thus a less stable value representation. The same price volatility situation but with longer periods is present in the fossil fuel markets (especially for oil but also for natural gas).

Arguably though, this volatility is not reflective of fundamentals - the energetic value of a kilowatt hour is the same irrespective of time of use especially for storable fuels - but rather a distortion arising from the existing infrastructure based on underpriced fossil fuel energy. Valorizing energy through an energy-credit ecurrency addresses this distortion at a fundamental level and facilitates the adoption of existing technologies to adjust demand and supply much more flexibly than what current market conditions have so far permitted. Nevertheless, in instances of temporal energy scarcity the price of energy should vary reflecting this. The Ergo concept addresses this price variation through the asymmetric spot market (cf. see Progression from Credit to Currency for 


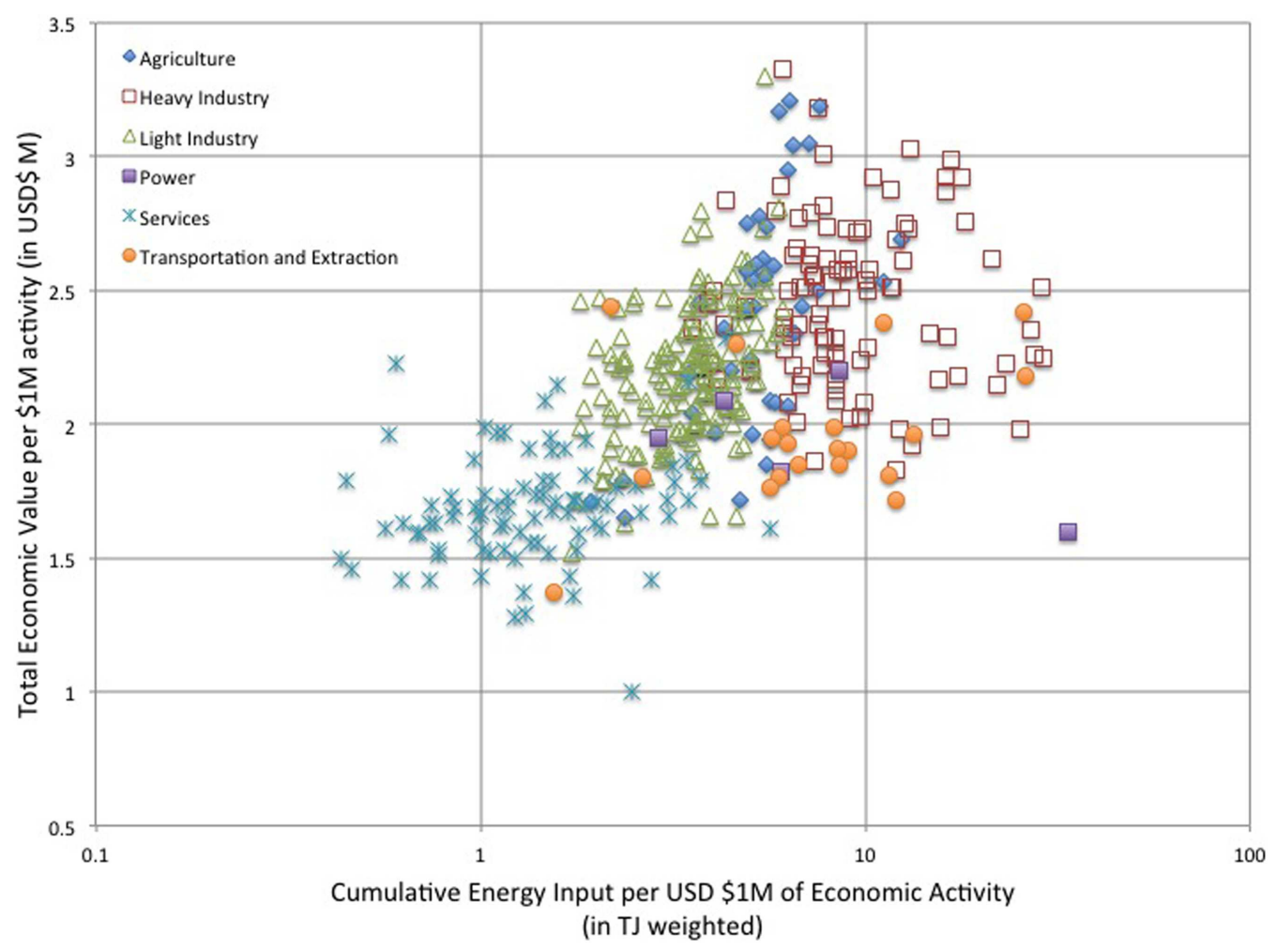

FIGURE 2 | Lifecycle correlation between economic value-added and energy input

the Ergo Concept). Finally, this dynamic does not affect energyreferenced currencies since they use long-term aggregation of all energy resources.

\section{CONCLUSION}

A SET from a finite energy resource base to an ER flow requires a significant rate of investment in energy generation infrastructure. The current global rate is approximately an order of lower magnitude indicating a failure of the current market mechanisms to adequately price future energy availability. Continuing this trend may lead to an energy trap for an economic system that is loosely coupled to ecosystem limits because the wave of over-consumption locks-in inefficient infrastructure and the availability of credit veils and enables the prolongation of this state despite the changing energy fundamentals. With the beginning of contraction, the situation reverses as credit becomes suddenly withdrawn exacerbating the underinvestment in the transition mechanisms and leads to a reinforcing cycle of further contraction as energy availability diminishes.

Energy-backed e-currency systems (energy-credits) provide a functional mechanism for communities that need to achieve a local SET by pursuing aggressive ER targets. These systems can be used for short-term energy management as well as mediumterm energy planning. Nevertheless, they remain complementary currencies operating in the sidelines of the broader monetary system. As a result, they are subject to the credit cycle and cannot limit "wasteful" consumption during a credit boom nor can they effectively address underinvestment in transition mechanism during a recession.

To affect larger-scale SET, a more drastic transformation is needed in which energy-referenced currency can play a key role. Such a scenario would require monetary reform that decouples the monetary and credit functions (known as the "Chicago Plan"), which would use the total current and future energy supply - potentially including crops and biomass - as reference for adjusting the money supply (especially debt extension). Such a system provides a self-balancing, market-based mechanism that incentivizes adequate investment to sustain current energy consumption patterns. While, other transition mechanisms like FITs and emissions trading systems have been very successful in bringing down the costs of ER through economies of scale and learning, they are not capable of limiting the credit side of the economic system something that the energy-referenced currency could do.

Circulation of an energy currency would not drastically change the relative valuations of the majority of products and services available today as there is already a fairly consistent correlation between total lifecycle energy input and economic value-added. It would affect the relative valuation of energy intensive products produced through reliably cheap energy sources (like cement and steel) but this would arguably be a cost internalization. Importantly, it would resolve the seeming paradox of zero energy costs due to the merit order effect for systems with high ER penetration and baseload power producers by weighting more long-term energy availability and essentially forcing a paradigm shift from 
energy pricing under an abundant energy regime to one that is rationed.

Rifkin (2008) suggests that the confluence of technological progress in information technology and energy supply was instrumental in initiating distinct "revolutions" or periods of accelerated and qualitative different societal development. In this case, he identifies the Internet, distributed energy generation, and smart grids as the catalysts for the "third industrial revolution." Energy-backed or referenced currency systems can build on the very same components to realign the financial world with the limits of the physical world. Energy-credit systems can meet the needs of communities that have defined energy constraints, ER resources, and smart infrastructure. Energy-referenced currencies are likely to evolve from or in parallel to these pilot applications as top-down government effort to control credit cycles by matching debt to the ecosystem limits and as a result incentivizing sufficient rates of ER infrastructure build-out.

\section{ACKNOWLEDGMENTS}

This work was supported by the Masdar Institute and benefited from conversations with numerous colleagues at the Global Energy Systems Conference 2013, the Quoin Complementary Currencies for Policy Makers conference in 2013, the Tesla International Social Transformation Conference in 2012. The author acknowledges the support of Denes Csala for his support in automating the collection of the EIOLCA data points. The author would like to thank the two reviewers and the editor whose comments and suggestions were critical in improving the clarity and presentation of the argument.

\section{REFERENCES}

Allen, W. R. (1993). Irving fisher and the 100 percent reserve proposal. J. Law Econ. 36, 703-717. doi:10.1086/467295

Arrow, K. J., Dasgupta, P., Goulder, L. H., Mumford, K. J., and Oleson, K. (2012), Sustainability and the measurement of wealth. Environ. Dev. Econ. 17, 317-353. doi:10.1017/S1355770X12000137

Barca, S. (2011). Energy, property, and the industrial revolution narrative. Ecol. Econ. 70, 1309-1315. doi:10.1016/j.ecolecon.2010.03.012

Bardi, U. (2009). Peak oil: the four stages of a new idea. Energy 34, 323-326. doi:10.1016/j.energy.2008.08.015

Bayoumi, T., Eichengreen, B., and Taylor, M. P. (1996). Modern Perspectives on the Gold Standard. Cambridge, UK: Cambridge University Press.

Benello, C. G., Swann, R. S., Turnbull, S., and Morehouse, W. (1989). Building Sustainable Communities: Tools and Concepts for Self-Reliant Economic Change. TOES Books. Available at: http://agris.fao.org/agris-search/search/display.do?f= 1991/US/US91299.xml;US9102272

Benes, J., and Kumhof, M. (2012). The Chicago Plan Revisited. SSRN Scholarly Paper ID 2169748. Rochester, NY: Social Science Research Network. http: //papers.ssrn.com/abstract=2169748

Benichou, L., and Mayr, S. (2014). Rogeaulito: a world energy scenario modeling tool for transparent energy system thinking. Front. Energy Res. 1:13. doi: 10.3389/fenrg.2013.00013

Butler, L., and Neuhoff, K. (2008). Comparison of feed-in tariff, quota and auction mechanisms to support wind power development. Renew. Energy 33, 1854-1867. doi:10.1016/j.renene.2007.10.008

CMU-GDI. (2008). Carnegie Mellon University Green Design Institute Economic Input-Output Life Cycle Assessment (EIO-LCA), US 2002 Producer Price Model. Available at: http://www.eiolca.net

Collins, J. R., Schuster, L., and Greenham, T. (2012). Energising Money: An Introduction to Energy Currencies and Accounting. London: New Economics Foundation.

Common, M., and Perrings, C. (1992). Towards an ecological economics of sustainability. Ecol. Econ. 6, 7-34. doi:10.1016/0921-8009(92)90036-R
Dale, M., and Benson, S. M. (2013). Energy balance of the global photovoltaic (PV) industry - is the PV industry a net electricity producer? Environ. Sci. Technol. 47, 3482-3489. doi:10.1021/es3038824

Dale, M., Krumdieck, S., and Bodger, P. (2011). Net energy yield from production of conventional oil. Energy Policy 39, 7095-7102. doi:10.3168/jds.2011-4283

Daly, H. E. (1996). Beyond Growth: The Economics of Sustainable Development. Boston, MA: Beacon Press.

Daly, H. E. (1985). "The economic thought of Frederick Soddy," in Frederick Soddy (1877-1956): Early Pioneer in Radiochemistry (Chemists and Chemistry), ed. G. B. Kauffman (Springer). Available at: http://link.springer.com/chapter/10.1007/ 978-94-009-5297-3_14

de Almeida, P., and Silva, P. D. (2009). The peak of oil production - timings and market recognition. Energy Policy 37, 1267-1276. doi:10.1016/j.enpol.2008.11.016

Doukas, H., Flamos, A., Karakosta, C., and Psarras, J. (2010). Establishment of a European energy policy think-tank: necessity or luxury? Int. J. Global Energ. Issues 33, 221-238. doi:10.1504/IJGEI.2010.036958

Doukas, H., Patlitzianas, K. D., Kagiannas, A. G., and Psarras, J. (2008). Energy policy making: an old concept or a modern challenge? Energy Sources 3, 362-371. doi:10.1080/15567240701232378

Douthwaite, R. (2011). Degrowth and the supply of money in an energy-scarce world. Ecol. Econ. Available at: http://www.sciencedirect.com/science/article/pii/ S0921800911001297

Douthwaite, R. (1999). The Ecology of Money. Totnes: Green Books.

Ellerman, A. D., and Buchner, B. K. (2007). The European Union emissions trading scheme: origins, allocation, and early results. Rev. Environ. Econ. Pol. 1, 66-87. doi:10.1093/reep/rem003

Finn, M. G. (2000). Perfect competition and the effects of energy price increases on economic activity. J. Money Credit Bank 32, 400-416. doi:10.2307/2601172

Fleming, D. (2005). Energy and the Common Purpose: Descending the Energy Staircase with Tradable Energy Quotas (TEQs). London: The Lean Economy Connection.

Georgescu-Roegen, N. (1993). "The entropy law and the economic problem," in Valuing the Earth: Economics, Ecology, Ethics, eds H. E. Daly and K. N. Townsend (Cambridge, MA: MIT Press), 74-87.

Graeber, D. (2011). Debt: The First 5,000 Years. Brooklyn, NY: Melville House.

Haar, L. N., and Haar, L. (2006). Policy-making under uncertainty: commentary upon the European Union emissions trading scheme. Energy Policy 34, 2615-2629. doi:10.1016/j.enpol.2005.07.003

Hall, C. A., and Klitgaard, K. A. (2011). Energy and the Wealth of Nations: Understanding the Biophysical Economy. New York: Springer.

Hamilton, J. D. (1983). Oil and the macroeconomy since World War II. J. Polit. Econ. 91, 228-248. doi:10.1086/261140

Hamilton, J. D. (2009). Causes and Consequences of the Oil Shock of 2007-08. Cambridge, MA: National Bureau of Economic Research.

Hart, S. L., and Milstein, M. B. (1999). Global sustainability and the creative destruction of industries. Sloan Manage Rev. 41, 23-33.

IPCC. (2007). Climate Change 2007: The Physical Science Basis. IPCC WGI Fourth Assessment Report. Available at: http://www.slvwd.com/agendas/Full/ 2007/06-07-07/Item\%2010b.pdf

ISTC. (2012). "Tesla energy currency conference proceedings," in Energy as the Fundamental Measure of Price, Cost and Value. Split. Available at: http:// teslaconference.com/materials.html

Jevons, W. S. (1885). Money and the Mechanism of Exchange. Vol. 17. New York: Appleton and Company.

Kim, K. K., and Lee, C. G. (2012). Evaluation and optimization of feed-in tariffs. Energy Policy 49, 192-203. doi:10.1016/j.enpol.2012.05.070

Lietaer, B. A. (2001). The Future of Money: A New Way to Create Wealth, Work and a Wiser World. London: Random House.

Maggio, G., and Cacciola, G. (2009). A variant of the Hubbert curve for world oil production forecasts. Energy Policy 37, 4761-4770. doi:10.1016/j.enpol.2009.06. 053

Marechal, F., Favrat, D., and Jochem, E. (2005). Energy in the perspective of the sustainable development: the $2000 \mathrm{w}$ society challenge. Resour. Conservat. Recycl. 44, 245-262. doi:10.1016/j.resconrec.2005.01.008

Murray, J., and King, D. (2012). Climate policy: oil's tipping point has passed. Nature 481, 433-435. doi:10.1038/481433a

Nakamoto, S. (2008). Bitcoin: A Peer-to-Peer Electronic Cash System. Available at: http://bitcoin.org/bitcoin.pdf 
North, P. (2006). Alternative Currency Movements as a Challenge to Globalisation? A Case Study of Manchester's Local Currency Networks. Ashgate Publishing, Ltd.

Oikonomou, V., Flamos, A., Gargiulo, M., Giannakidis, G., Kanudia, A., Spijker, E., et al. (2011). Linking least-cost energy system costs models with MCA: an assessment of the EU renewable energy targets and supporting policies. Energy Policy 39, 2786-2799. doi:10.1016/j.enpol.2011.02.050

Pearce, D. (1991). The role of carbon taxes in adjusting to global warming. Econ. J. 101, 938-948. doi:10.2307/2233865

Reiche, D. (2010). Renewable energy policies in the gulf countries: a case study of the carbon-neutral "Masdar City" in Abu Dhabi. Energy Policy 38, 378-382. doi:10.1016/j.enpol.2009.09.028

Rifkin, J. (2008). The third industrial revolution. Eng. Technol.3, 26-27. doi:10.1049/ et: 20080718

Rotemberg, J. J., and Woodford, M. (1996). Imperfect Competition and the Effects of Energy Price Increases on Economic Activity. Cambridge, MA: National Bureau of Economic Research.

Scott, H. (1933). Technology smashes the price system. Harper's Magazine 166, 129-144.

Sgouridis, S., and Kennedy, S. (2010). Tangible and fungible energy: hybrid energy market and currency system for total energy management. A Masdar City case study. Energy Policy 38, 1749-1758. doi:10.1016/j.enpol.2009.11.049

Tainter, J. A. (2004). The Collapse of Complex Societies. Cambridge, UK: Cambridge University Press.
Wrigley, E. A. (2010). Energy and the English Industrial Revolution. Cambridge, UK: Cambridge University Press.

Zhang, Z. X., and Baranzini, A. (2004). What do we know about carbon taxes? An inquiry into their impacts on competitiveness and distribution of income. Energy Policy 32, 507-518. doi:10.1016/S0301-4215(03)00152-6

Conflict of Interest Statement: The author declares that the research was conducted in the absence of any commercial or financial relationships that could be construed as a potential conflict of interest.

Received: 24 September 2013; accepted: 11 February 2014; published online: 26 February 2014.

Citation: Sgouridis S (2014) Defusing the energy trap: the potential of energydenominated currencies to facilitate a sustainable energy transition. Front. Energy Res. 2:8. doi: 10.3389/fenrg.2014.00008

This article was submitted to Energy Systems and Policy, a section of the journal Frontiers in Energy Research.

Copyright $($ C 2014 Sgouridis. This is an open-access article distributed under the terms of the Creative Commons Attribution License (CC BY). The use, distribution or reproduction in other forums is permitted, provided the original author(s) or licensor are credited and that the original publication in this journal is cited, in accordance with accepted academic practice. No use, distribution or reproduction is permitted which does not comply with these terms. 